\title{
CORRECTION
}

\section{Correction to: Fewer patients undergo surgery when adding a comprehensive geriatric assessment in older patients with a hip fracture}

\author{
Babette C. van der Zwaard ${ }^{1}$ (D) . Charlotte E. Stein ${ }^{2}$. Janet E. M. Bootsma ${ }^{2} \cdot$ Hendrikus J. A. A. van Geffen ${ }^{3}$. \\ Conny M. Douw ${ }^{1}$. Carolina J. P. W. Keijsers ${ }^{2}$
}

Published online: 30 November 2019

○) Springer-Verlag GmbH Germany, part of Springer Nature 2019

\section{Correction to: Archives of Orthopaedic and Trauma Surgery https://doi.org/10.1007/s00402-019-03294-5}

The original version of this article unfortunately contained a mistake. The presentation of Fig. 1 was incorrect. The correct version of Fig. 1 is given below.

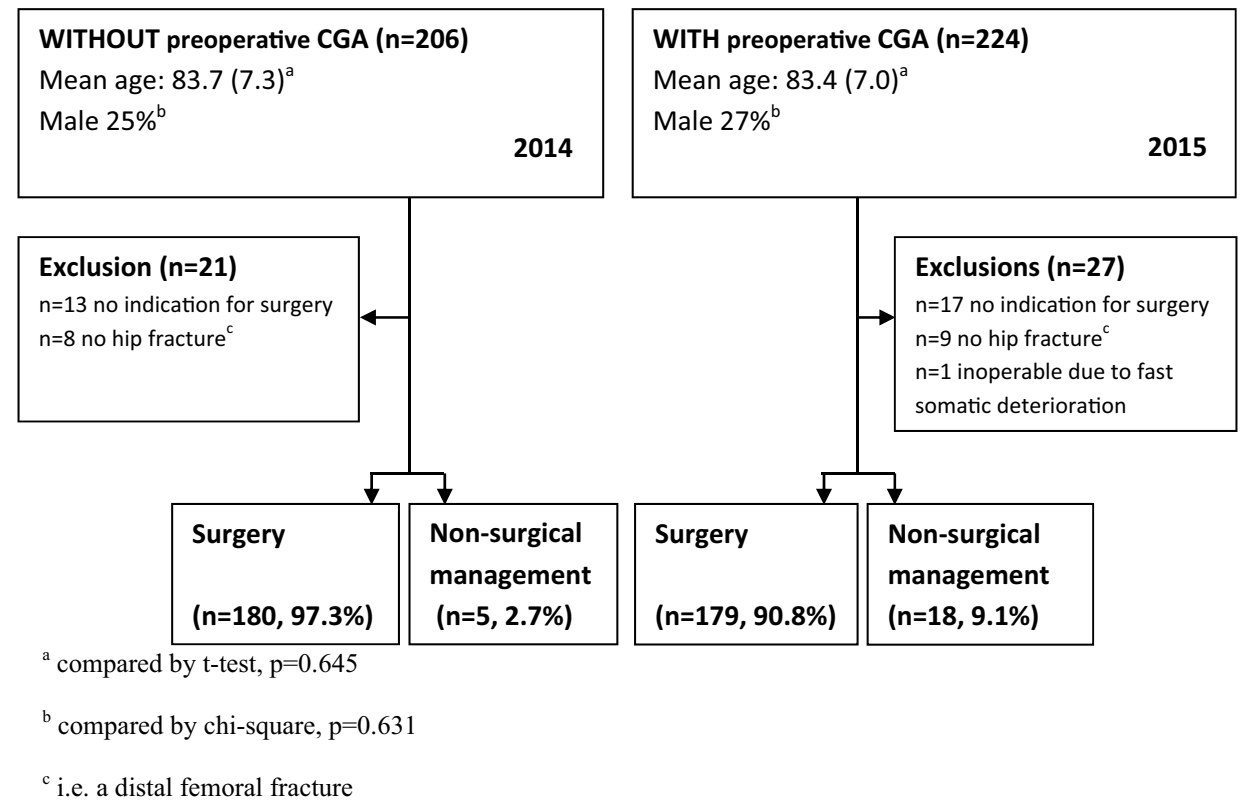

Fig. 1 Flowchart of inclusions in the study: all patients are $\geq 70$ years with a hip fracture and received a pre-operative comprehensive geriatric assessment (CGA) or not

The original article can be found online at https://doi.org/10.1007/ s00402-019-03294-5.

Babette C. van der Zwaard

b.v.d.zwaard@jbz.nl

1 Department of Orthopedic Surgery, Jeroen Bosch Hospital, PO Box 90153, 5200 ME 's-Hertogenbosch,

The Netherlands
Publisher's Note Springer Nature remains neutral with regard to jurisdictional claims in published maps and institutional affiliations.

2 Department of Geriatric Medicine, Jeroen Bosch Hospital, 's-Hertogenbosch, The Netherlands

3 Department of Surgery, Jeroen Bosch Hospital, 's-Hertogenbosch, The Netherlands 